\title{
Aufgabe und Durchführung einer Theologie des Neuen Testaments
}

\author{
Hrsg. v. Cilliers Breytenbach u. Jörg Frey
}

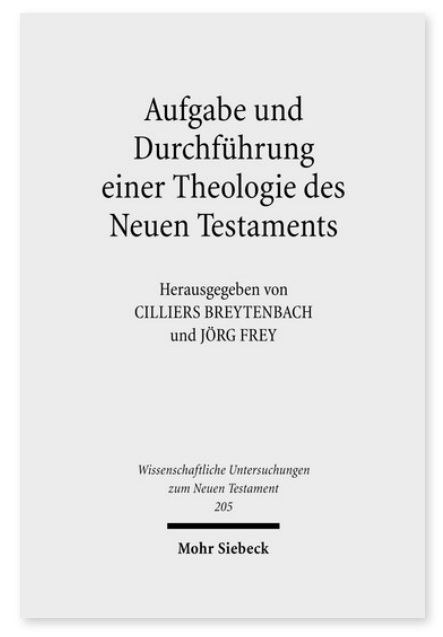

2007. XII, 364 Seiten. WUNT I 205

ISBN 978-3-16-151494-4

DOI 10.1628/978-3-16-151494-4

eBook PDF 139,00€

ISBN 978-3-16-149252-5

Leinen $139,00 €$
Berechtigung, Aufgabe, Aufbau und Durchführung einer »Theologie des Neuen Testaments sind auch nach über 200 Jahren der Diskussion heftig umstritten. Während die einen nach religions- oder theologiegeschichtlichen Alternativen einer solchen Gesamtdarstellung der neutestamentlichen Wissenschaft suchen, fragen andere Autoren dezidiert nach der Einheit der neutestamentlichen Theologie in der Vielfalt der Entwürfe. Die Autoren der Beiträge dieses Sammelbandes erörtern die strittigen Fragen in internationaler und ökumenischer Perspektive und im Gespräch mit der Systematischen Theologie. Neben einigen programmatischen Entwürfen steht dabei die 2002 erschienene Theologie des Neuen Testaments von Ferdinand Hahn im Brennpunkt der Diskussion.

\section{Inhaltsübersicht}

\section{I. »Theologie des Neuen Testaments« in der Diskussion:}

Jörg Frey: Zum Problem der Aufgabe und Durchführung einer Theologie des Neuen Testaments - Rudolf Hoppe:

Überlegungen zur Theologie des Neuen Testaments aus katholischer Sicht - John Reumann : New Testament Theology, within Biblical Theology and Beyond, for Ecclesial and Ecumenical Uses - Robert Morgan : Made in Germany: Towards an Anglican Appropriation of an Originally Lutheran Genre

II. Das Für und Wider einer »Theologie des Neuen Testaments"

Jürgen Becker: Theologiegeschichte des Urchristentums - Theologie des Neuen Testaments - Frühchristliche Religionsgeschichte - Jens Schröter: Die Bedeutung des Kanons für eine Theologie des Neuen Testaments. Konzeptionelle Überlegungen angesichts der gegenwärtigen Diskussion - François Vouga: Die Aufgaben der Theologie des Neuen Testaments. Verstehen als interdisziplinäre Kunst der Interpretation - Heikki Räisänen : Towards an Alternative to New Testament Theology: Different 'Paths to Salvation' - Charles Kingsley Barrett: Historia Theologiae Genetrix - James D. G. Dunn: Not so much 'New Testament Theology' as 'New Testament Theologizing' - Johan S. Vos: Theologie als Rhetorik. III. Die eine »Theologie des Neuen Testaments« - ein Gespräch mit der systematischen Theologie Notger Slenczka: Systematische Bemerkungen über die Aufgabe und den Ansatz einer Theologie des Neuen Testaments am Beispiel des Entwurfes von Ferdinand Hahn - Friedrich Wilhelm Horn: Die Nachfolgeethik Jesu und die urchristliche Gemeindeethik. Ihre Darstellung innerhalb Ferdinand Hahns Theologie des Neuen Testaments - Peter Neuner: Fundamentaltheologische Implikationen einer Theologie des Neuen Testaments - Wolf Krötke : Erlaubt die »Einheit« der Theologie des Neuen Testaments eine eindeutige Hoffnung? Eine Frage an Ferdinand Hahn - Karl Kardinal Lehmann : Die Bedeutung von Bibel und Bibelwissenschaft für Kirche und Gesellschaft - Ferdinand Hahn : Nachwort

Jörg Frey Geboren 1962; 1996 Promotion; 1998 Habilitation; Professur für neutestamentliche Wissenschaft mit den Schwerpunkten Antikes Judentum und Hermeneutik an der Theologischen Fakultät der Universität Zürich und Research Associate der University of the Free State, Bloemfontein/ZA.

https://orcid.org/0000-0001-6628-8834

Cilliers Breytenbach Geboren 1954; Studium der Philologie, Philosophie und Theologie in Pretoria und München; 1983 Promotion; 1986 Habilitation; 1990-2019 Universitätsprofessor für Literatur, Religion und Zeitgeschichte in Berlin; seit 2003 außerplanmäßiger Professor für New Testament and Ancient Studies an der Stellenbosch University. https://orcid.org/0000-0002-6322-9473

Jetzt bestellen:

https://mohrsiebeck.com/buch/aufgabe-und-durchfuehrung-einer-theologie-des-neuen-testaments-9783161514944? no_cache=1 order@mohrsiebeck.com Telefon: +49 (0)7071-923-17 Telefax: +49 (0)7071-51104 